\title{
The Role of Social Media in Creativity Management in Advertising Agencies
}

Andrea Rubik, Faculty of Economics and Business, University of Zagreb, Croatia*

\begin{abstract}
Social media has changed traditional advertising, driving, expanding, and shaping creativity in an advertising agency and challenging its existing creativity management. As such, it represents one of the most transformative impacts of information technology on advertising agency business and its management. Social media has altered dramatically the ways organizations relate to the markets and society, creating a new world of possibilities and challenges many aspects of an advertising agency, from organization and operations to innovation and creativity management. Furthermore, it outlines a broad research agenda for understanding the relationships among social media, advertising agencies, and creativity management. The goal of the paper is to propose the framework featuring the role of social media in creativity management and the connection with the creative process and successful management of an advertising agency. The contribution of this paper is the exploration of the social media role in advancing creativity management in advertising agencies.
\end{abstract}

\section{KEYWORDS}

Advertising Agency, Creativity Management, Social Media

\section{INTRODUCTION}

Over the last decade, social media has dramatically shifted the media environment, changing how we communicate, collaborate, and create (Di Gangi and Wasko 2009; Hanna et al., 2011). Social media refers to digital technologies emphasizing user-generated content, interaction via web-based platforms (Boyd and Ellison, 2007; Kaplan and Haenlein, 2010) that has diversified communication interaction (Mangold and Faulds, 2009) and has a transformative impact on adverting agency business (Wind and Sharp, 2009; Freytag and Clarke, 2012). Once dominated by mass media such as television, radio, print, and outdoor, the advertising industry has expanded to include new technologies and digital media that are more dynamic, interactive, and fragmented (Mangold and Faulds, 2009; Knoll, 2016). Advertising agencies also have adopted new models and expanded their services according to new markets and advertisers' needs (Okazaki and Taylor, 2013; Wind and Sharp, 2009; Hanna et al., 2011). In addition, specialized digital agencies have been established to offer new expertise and address the new forms of communication and advertising as traditional agencies were slow or resistant to accommodate (Durkin and Lawlor, 2001; Freytag and Clarke, 2012). As a result, advertising agencies quickly enhanced creativity to digital advertising as advertising shifted from traditional to digital media space. 
The latest technologies and social media have significant implications on the marketing and advertising industry (Tapp and Hughes, 2004; Hanna et al., 2011); increasingly transforming the way agencies relate to employees and build relationships with remote talents, collaborate, and crowdsource new ideas (Di Gangi and Wasko 2009; Argueta and Pérez-Latre, 2018). Moreover, social media developments enabled higher interactivity, customization, diverse interactions and generated various meanings for marketers and advertisers (Kotler and Lee, 2008). As consumers have shifted attention and advertisers have expanded their requirements, advertising agencies are changing their business models, organization, and services (Durkin and Lawlor, 2001; Freytag and Clarke, 2012). With these shifts in demands and new markets, advertising agencies are developing their expertise in a new set of skills and services, incorporating digital and new media strategies into integrated campaigns. These new tasks require new knowledge and new types of experts that play new roles in the creative process (Montalvo, 2011), and advertising agencies can no longer build on its existing skills, mindsets, culture, and knowledge (Anderson and Tushman, 1990; Leonard-Barton, 1992). Therefore, it is interesting to explore social media possibilities and how advertising agencies adjust their activities regarding creative process and creativity management accordingly.

Social media provides and creates novel opportunities for individuals and communities, but also for firms and organizations. However, these possibilities bring challenges in agency management practice, creative processes, and their application at individual, group, organizational and cultural levels. Placing social media into organizational communication preferences expands the possibilities employees have at their disposal to display, test, and validate their work. Engaging employees through social media, they accept augments learning while their expertise with social media increases the likelihood of being more proactive and innovative (Sigala and Chalkiti 2015). Besides, interactivity in the communication of brands and consumers is a process where the business clients benefit from the creative and innovative deliverables produced by an advertising agency.

This paper focuses on social media and the use of its possibilities to enhance creativity and innovation that take place in an advertising agency. The purpose of this paper is to achieve a better understanding of the role of social media in creativity management in advertising agencies and propose a framework for creativity management that includes social media contributing to creativity in advertising agencies.

New technologies and consumer behaviour changes have significant implications for the advertising industry (Tapp and Hughes, 2004), giving rise to the need for advertising agencies to revisit creativity management and explore new ways of engaging all stakeholders during the project and creative process. On the one hand, engaging stakeholders in advertising activities have opened possibilities for novel creative opportunities; on the other hand, it has also brought challenges to advertising agencies regarding management and new activities in creative work. Furthermore, there are opportunities and challenges to advertising agencies and practitioners in responding to new technologies and increasing social media platforms (West et al., 2019).

While many researchers have examined social media advertising (see Kim and McMillan, 2008; Ha, 2008; Dwivedi et al., 2015; Okazaki and Taylor, 2013; Voorveld et al., 2018; Alalwan, 2018; Lee and Hong 2016) and new ways of advertising made possible through social media (Li, 2011; Khang et al., 2012), no previous study has addressed the role of social media in the context of the creativity management and arising creative process possibilities in advertising agencies. In addition, it is interesting to examine creativity management in terms of new activities and collaboration opportunities brought by advances in social media. Therefore, by examining changes influenced by social media, this paper explores the role of social media for organization and creative process to advance creative management in advertising agencies and stimulate research on the relationship between social media and creativity management.

The paper examines activities that can be undertaken in interaction with social media for the purpose of creativity and innovation and which use the role of social media in creativity management in advertising agencies. The paper is structured in four parts. The first part of the paper is the introduction, 
and it is followed by the second part that explores the theoretical segment of creativity management and the social media phenomenon. The third part of the paper discusses social media's role in creativity management in an advertising agency. The fourth part of the paper presents the creativity management framework that includes the role of social media, and the last part is the conclusion.

\section{BACKGROUND}

\section{Creativity Management}

Establishing a fertile ground for creativity in an organization and among leaders is the first and most important in building a sustainable business for the future, and social media plays a significant role in supporting traction on sustainability (e.g., Pejić Bach et al., 2020). Creativity in the workplace is typically defined as valuable and novel ideas addressing a specific problem (Amabile, 1997) or a process leading to a new product to realize market demands (Zhou, 2008). Creativity in organizations may include already seen approaches adopted from elsewhere that have been modified in some specific way to address a job to be done, and they are thus new to the organization (Amabile, 1997; Shalley and Zhou, 2008). According to Anderson et al. (2014), creativity and innovation are integral parts of the same process and, as such, are defined as "the process, outcomes, and products of attempts to develop and introduce new and improved ways of doing things. The creativity stage of this process refers to idea generation, and innovation to the subsequent stage of implementing ideas toward better procedures, practices, or products" (Anderson et al., 2014, pp.4). Hence, creativity stands for the generation of novel and valuable ideas; innovation refers to the production of creative ideas as the first stage and implementation as the second stage (Amabile, 1997). From the business and organizational perspective, creativity has become an essential determinant of a firm's performance, sustainability and essential to its successful business growth (Anderson et al., 2014; Zhou, 2008).

Creativity in business is essential for business results, success, sustainability, and the 21 stcentury global environment. Therefore, ideation has become an impactful competitive advantage as organizations seek to foster creativity and innovation to solve problems (Rickards and Moger, 2006; Makri and Scandura, 2010). Over time, repeated use of creativity in problem-solving and business develops and strengthens the leader's creative thinking skills (Makri and Scandura, 2010; Puccio et al., 2011). Creative leadership deliberately engages one's imagination to define and guide a team toward a novel goal - a direction that is new for the team (Puccio et al., 2010), while creativity management is a management process whose goals are to understand the problem and design solutions through ideation, testing, implementing, and creating impact through solutions and values. While many advertising agencies already affect the creativity of their talents, experts, and managers, the emphasis of creativity management is to framework activities and processes to increase creativity and innovation. As mentioned previously, an important focus is to leap creativity from a project to an organization and manage it with increased innovation in business performance.

In an advertising agency, creativity is often viewed as a 'connecting the dots' activity that seeks new solutions and ideas (Horsky, 2006; Hipperson, 2012). It is about solving a problem that often entails sudden realization, inspiration, insight, recognition, or comprehension. Problem-solving is also a skill that can be learned by having relevant knowledge and experience and improved practice. Even though some people are more proactive and open to new approaches to problem-solving, organizations can do much in the creativity management space and other activities that provide a welcoming climate for those working on new ideas (Makri and Scandura, 2010; Xu and Rickards, 2007). Also, leaders and organizations can do a lot to increase creativity (Rickards and Moger, 2006) and initiatives by fostering activities that enhance market and environment understanding, learning, idealization, testing, and problem-solving through value delivery. Viewed in this way, the increase in creativity in advertising agencies is essentially the result of managerial efforts for various activities in the creative process. 
Creative leaders accept constant change and learning (Basadur, 2004). As Basadur said, creative leadership refers to constant improvements in leading and understanding different needs, diverse ways of thinking, and managing change (Basadur, 2004). Such leaders do not avoid the complexity and transparency in the communication brought by social media. On the contrary, they use social media to improve the creative process, encourage new activities, new ways of working, new collaborations, and constantly look for new opportunities. They are also motivators, knowledge creators, and links in managing a complex creative process involving internal and external stakeholders (Ackoff and Greenberg, 2008). Therefore, creativity management in an advertising agency is inevitable, and leaders could benefit from creativity management that includes the active role of social media as a proactive approach to future business. Creative leaders should embrace new technologies, new ways of collaborating, communicating, working, and managing (Makri and Scandura, 2010).

Creative management and creativity do not happen by accident. Both come from complex environments and interactivity, which is a significant element in today's advertising business. Leaders who are serious about success in uncertain times can lead teams to bring diverse perspectives that advance creativity management in an organization and lead to innovative thinking. With enhanced importance of creativity and innovation for the future of creative problem-solving, success requires a continuous creation of new ideas and critical thinking and the organization which advances activities and processes with technology, digital and social media.

\section{The Phenomenon of Social Media}

Out of the worldwide population, approximately $48.3 \%$ of the global population were social media users in 2020 (Statista, 2020). Social media is now clearly a part of our daily lives, and social networking is one of the most popular online activities worldwide, with global social media audiences amounted to 3.6 billion users in 2020 (Statista, 2020). Social media is an omnipresent element of society and business. It has changed how organizations communicate, collaborate, and create, and as that represents one of the most transformative impacts of new technologies on business, inside and outside the organization (Tajudeen et al., 2018). Moreover, social media has dramatically changed the ways organizations relate to the market and consumers, creating new opportunities for all aspects of business, from workflow and ideation to organization and human resource management (Voorveld et al., 2018; Holt, 2016; Kaplan and Haenlein, 2010). In the marketing space, social media has been an essential part of advertising campaigns and interaction with consumers (Mangold and Faulds, 2009). However, the interactive power of social media extends beyond aspects of communication, marketing, and advertising.

The development of new technologies and social media has broad implications for communication and will impact the creative industry in terms of organization and management (Tajudeen et al., 2018). In addition, the algorithms on which social media is based, the way users interact with social networks, and the growing value of interactions within social media change the way of working, organization, and managerial practices that are interesting for business and research.

Technology continues to evolve, changing the way and amounts of data storage and processing, resulting in various data-based tools. This data-driven infrastructure is the basis of the emerging Web 3.0, which uses complex algorithms, incredibly high computing power, and machine learning to scan and synthesize data from various databases to change the user experience (Berners-Lee et al., 2001). Thus, social media tools have become more advanced and adaptable, and users frequently communicate without a clear sense of interaction with another human or computer program behind the person onscreen (Lim and Reeves, 2010). In addition, social media increasingly takes advantage of its channels' ubiquitous and personal nature, changing the scale of communication interactions by allowing mass messages to be received, interpreted, and responded to interpersonally (Di Gangi and Wasko, 2009). With these foundations and possibilities, communication is designed for a mass audience, using webbased platforms to connect with large and diverse audiences (Kaplan and Haenlein, 2012) where users create, collaborate, publish, and edit different content. All mentioned spans possibilities for 
business collaboration, remote working, testing ideas or concepts, communication with consumers and launching products.

Social media has undergone tremendous development and growth. It influences every business and consumer segment, regionally and globally (Kotler and Lee, 2008). Moreover, it has led to joint decision-making, which is defined as consumers making their decisions in the environment around them, such as family, friends, and co-workers (Alalwan, 2018; Dessart et al., 2015; Kaplan and Haenlein, 2010). Traditionally, consumers make purchasing decisions based on information they receive through the mass media (television, print, radio, outdoor), but nowadays, social networks can influence consumer purchasing decisions (Lee and Hong, 2016). Today's consumers are creators and actively shape media content regardless of socio-demographic or geographic boundaries. They have become creators encouraged to contribute and access any content whenever and wherever they want across various social networking platforms (Dessart et al., 2015) transforming communication with firms and brands (Krishnamurthy and Dou, 2008).

Social media has transformed social interactions with changing workflow, shaping organizations, and creating new markets (Creeber and Martin, 2008). The rise of various digital media and platforms has contributed to a new form of the networked society. It has been described as the digital culture, values, practices, and expectations people use to communicate and interact (Miller, 2020). In this new world of digital culture, people have become more than contributors. They are creators and designers of values and expectations through participation and interaction. For example, research has reflected how publicity from consumers through blogs and other social media platforms can substantially impact generating positive attitudes towards brands (Miller, 2020).

Today, people perceive information about products and services on social media as relevant and reliable, which significantly influences their purchasing decisions. Digital culture has brought a strong sense of personalization through individualization, interactivity, and enabling individuals to express their opinions. For example, influencers and bloggers become significant creators and producers of content that brands engage in their communication with the target audience. In these new forms of cooperation, interaction, and communication, it is increasingly difficult to delineate and define the roles and activities of media producers and consumers because they are constantly changing and depend on the context.

Social media has democratized the internet allowing individuals to express their opinion and share their content freely, moving to a new era of sharing and collective creativity (Kotler and Lee, 2008). Although the democratized impact of social media can be overstated, there is no doubt that digital technologies have changed the relationship between brands and consumers, therewithal cooperation between marketers and advertising agencies. Today, consumers reach for product information, interact with brands, and engage with advertising as part of their everyday lives. Social media enables them to express, participate in and co-create marketing activities for brands and with brands (Deuze, 2007). Through social media platforms, consumers regularly create and share information, communicate and generate content about diverse topics and brands.

Furthermore, social media is becoming a relevant source of information, enabling users to share content on social media as a credible source of information and peer-to-peer conversations or reviews as trusted to influence purchasing decisions (Creeber and Martin, 2008). With user-generated content and brand conversations as sources of information, marketers and advertisers do not control the conversation as a push medium but join and moderate conversations (Mangold and Faulds, 2009) and become active participants in brand communication.

\section{Changes in Advertising Agencies Due to Social Media}

Changes in the advertising industry are emerging by changes in the media landscape, how consumers interact with brands, new dimensions of community powers, and ways brands reach new markets (West et al., 2019; Jothi et al., 2011; WARC, 2021; IPA 2019). Social media is more interactive, measurable, and adaptable than traditional media and, as such, changed the media landscape. As a 
result, new communication possibilities encourage advertisers to expect new services, faster realization, and novel performance from advertising agencies. Besides, social media opens new communication channels among all advertising industry stakeholders - advertisers, agencies, research firms, and consumers (Kaplan and Haenlein, 2010). With the help of social media, agencies can add value to their creative process to provide new dimensions of creativity and innovation through their services (Lee and Hong, 2016).

Social media enables and demands from advertising agencies to tailor services to individual clients, both in creativity and in delivery for diverse clients and different business purposes (Hanna et al., 2011). In addition, a new organizational approach using social media in communication and business activities could contribute to better business decisions as organizations gain information, feedbacks, and testing possibilities (Hackley and Kover, 2007; West et al., 2019; Durkin and Lawlor, 2001). Therefore, advertising agencies are enabled to enrich their creativity and innovation (de Waal Malefyt and Morais, 2010) and improve creativity management through the framework that leverages the role of social media through activities in the following manner:

- Operations: Describes how advertising agencies use specific social media features; and how to implement these features to enable new technologies to amplify creativity and innovation to achieve business goals (e.g., crowdsourcing).

- Strategy: Describes how advertising agency uses social media and create strategies that best meet their needs or achieve their business goals (e.g., new services, partnerships, collaborations).

- Management: Describes how an advertising agency manages and allocates processes, talents, and technology needed to develop, deploy, use, and interact with social media to meet their needs or achieve business goals (e.g., learning, talent management).

Social media is transforming how advertising agency businesses relate to stakeholders, outsourcing experts when needed, and crowdsourcing new ideas. Moreover, it remodels learning within organizations, advances expertise, and accelerates innovation in developing new products (de Waal Malefyt and Morais, 2010). Social media has disrupted the advertising industry among many other industries and transformed advertising agencies (Freytag and Clarke, 2012; Horsky, 2006; Stuhlfaut and Windels, 2019).

\section{SOCIAL MEDIA AND CREATIVITY MANAGEMENT}

\section{The Advertising Agency Workflow Including Social Media}

Social media has introduced a new element in managing creativity in an advertising agency through adding new activities and transformation of existing processes and even revealed several new processes that support the development and evaluation of new ideas (Ashley and Tuten, 2015; Horsky, 2006). It should be noted that, although creativity management wants to increase participation, it does not expect or require everyone in the organization to create new ideas but that there is knowledge of the process and available information about the project.

Interactivity and collaboration for creativity and innovation are no longer just within the organization (Tajudeen et al., 2018) because expanded to the firm's environment and stakeholders. In that sense, there is the possibility of involving not only the client-advertiser but also the consumer. Although some stakeholders do not participate in the creative process, they are part of the creative process and have other significant roles in their organizations that are recognized in other contexts (Di Gangi and Wasko 2009). Therefore, the advertising agency workflow, which includes the role of social media in the creative process and innovation, contributes to understanding the problem, designing a solution, and diffusing it to the market (Figure 1). 


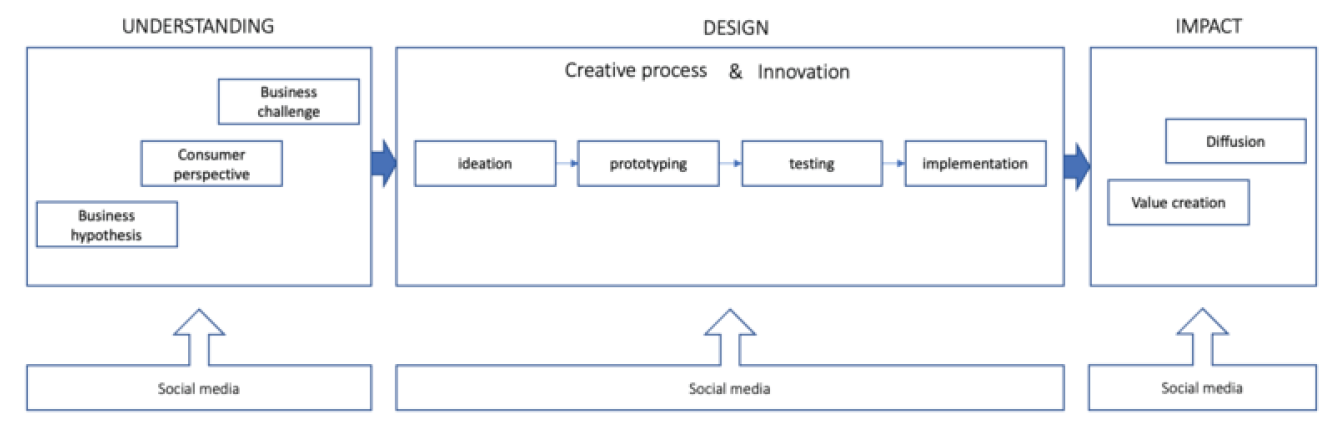

Figure 1 shows the creative process from Razzouk and Shute (Razzouk and Shute, 2012) expanded to advertising agency workflow and how it relates to social media. Creativity management focuses on the three parts of the creative process and innovation, from understanding the problem to designing solutions and creating the impact. The workflow also shows a "creative process that engages in opportunities to experiment, create and prototype models, gather feedback, and redesign" (Razzouk and Shute, 2012, p. 330) within of creativity management that stimulates and realize ideas to products: idea generation (ideation), prototyping, testing, and idea realization (implementation). These four elements are sequential and work in tandem.

\section{Social Media and Creativity in the Understanding Phase}

Social media has transformed how advertising agency operates and have influenced the creative process (Stuhlfaut and Windels, 2019) enabling operations to expand and efficiently conduct business activities beyond their organizational borders and in continuous and informal ways (Krishnamurthy and Dou 2008). Indeed, social media enables information, crowdsourcing, communication, and validation of ideas from various sources to create new ideas and solutions. Advertising agencies and their employees join social networks to stay informed professionally, participate in projects, or sharing experiences (Hanna et al., 2011). In addition, social media allows communication and interaction (Knoll, 2016; Kaplan and Haenlein, 2010), which is extensively used in advertising agency operations from preparation of a project all the way to deliverables. According to Roblek et al., organizations recognize the added value of social media, and social media is no longer just part of the service but also part of the organization and operation of the advertising agency related to specialized departments, professionals, and management (Roblek et al. 2013).

As digital crowds have become creators and influential cultural innovators, a new phenomenon of crowdsourcing culture (Holt, 2014) becomes a part of the creative process. Moreover, brands collaborate through crowdsourcing, monitor market needs, gather information, and benefit from dynamics in the marketplace. Interactivity becomes possible in every part of creativity management. It means the openness of the process to different teams or stakeholders, which is undoubtedly a challenge for new activities for management. Holt writes more about branding in the age of social media and that today there is a rise in crowdsourcing around almost any topic (Holt, 2014). Therefore, it can be assumed that crowdsourcing deflates traditional creativity management and makes social media activities and interactions in advertising agency management and organization valuable and even more powerful.

Changes in social behavior relating to social media implement both opportunities and challenges for creative industries such as content creation, communication, advertising, and production (Ashley and Tuten, 2015). Focusing on the advertising context, the social media environment has altered the 
relationship between marketers and consumers (Mangold and Faulds, 2009). Furthermore, content flows in two directions, from the brands to consumers and from consumers to firms. There are three principal components of the social media ecosystem: media convergence, participatory culture, and collective intelligence (Creeber and Martin, 2008). All three of these components indicate that the importance of participation and the community nature has required marketers and advertisers to rethink the role of consumers concerning content creation and consumption of messages (Creeber and Martin, 2008). Consumers' increasing engagement with content and draws technological, cultural, economic, and social impacts together (Ashley and Tuten, 2015; Dessart et al., 2015).

New technologies and consumers' behavioral changes significantly impact an advertising agency, requiring agencies to develop new ways of engaging consumers in the communication process (Knoll, 2016). Thus, advertising agencies are paying increasing attention to social media for marketing communication and advertising activities to be more competitive in this changing market environment (Kaplan and Haenlein, 2010). It is not only for competitiveness; social media becomes efficient for advertising, brand, and media investments as it delivers greater measurability in ROI, engagement, targeting, and micro-moment timing than traditional media (Kotler and Lee, 2008).

Social media can provide advertising tools for brands and help increase consumers' engagement, create interest, and stimulate word-of-mouth communication (Dessart et al., 2015). The new form of consumer culture created by social media has significant implications on advertising agencies' operations.

\section{Social Media and Creativity in the Design Phase}

Technology is advancing rapidly, impacting every area of advertising agency organization. From solving problems to creating products, social media rapidly affects advertising agencies, disrupts competitive categories, and even introduces new business models (Stuhlfaut and Windels, 2019). Changes in technology have always had significant impacts on the advertising business and agencies ' organizations and management. Since the 1950s, advertising agencies have been an innovation driving engine for the marketing and advertising industry. Still, accelerated social media growth has brought new challenges for advertising agency management and organization.

Social media tools improve, and organizations can utilize social media for gathering information or scanning consumers' interests, allowing better design, reacting faster, and more accurate targeting (Voorveld et al. 2018; Lee and Hong, 2016). Collecting and analyzing large amounts of real-time data also facilitate organizational monitoring and response (Lee and Hong, 2016), and interactivity through dialogue between advertising agencies and their stakeholders (Durkin and Lawlor, 2001; Gensler et al., 2013). Changes in the advertising industry and advertising agencies seem unavoidable in an era where social media is pivotal to survival for many brands and campaigns (Holt, 2016; Lee and Cho, 2020).

The omnipresence of social media will enable advertising agencies to communicate, manage and collaborate differently, internally with employees and externally with clients, collaborators, experts, or consumers. Moreover, elements and activities of social media directly impact the assessment of service quality and the intermediary role that knowledge management plays concerning social media elements or activities and the quality of services (Kašćelan et al., 2020). Rather than onsite facilitating communication and interaction, social media affords a virtual place for advertising agencies and individuals with common interests to engage in communications and interactions (Li, 2011; Ashley and Tuten, 2015; Steinkuehler and Williams, 2006).

Social media allows advertising agencies to conduct environmental scanning, monitoring and evaluating their business efforts, including employees, clients, collaborations, and stakeholders (Tajudeen et al., 2018; de Waal Malefyt and Morais, 2010). It enables advertising agencies to tap into a vast pool of talents and at the same time manage talent, culture, and stakeholders' relationships more interactively. As more advertising agencies implement proprietary intranet-based social media platforms due to remote work or geographical allocation, workflows also streamline in line with 
diverse communication and interaction (Li, 2011; Mangold and Faulds, 2009), providing a place for individuals and teams to share and collaborate around diverse professional interests, which encourages experimentation and learning (Tajudeen et al., 2018).

Changes in employees' interactions have inevitably led to new value systems within agency culture, characterized by a value system and shared expectations. Employees remix personal and professional, sharing and collecting information, their activities forming network empowered culture that is individualized yet connected (Deuze, 2007). Social media advances how employees interact internally in an advertising agency (Tajudeen et al., 2018), notably on projects for clients participating in diverse activities like gathering information or validation and influence the business through digital platforms.

The challenge for creative leaders today is integrating different disciplines of creativity and interactivity in advertising and organizational activities (Horsky, 2006; Rickards and Moger, 2006). The technical part includes the knowledge and skills required for task completion among different processes and technology, and the culture part refers to the demand for knowledge of the entire process from traditional and new media perspectives (Freytag and Clarke, 2012; Hipperson, 2012).

The challenges faced by the advertising agency require traditional advertising agencies to expand their range of services and to activate new ways to engage stakeholders in communication (Kaplan and Haenlein, 2010). Based on these challenges that advertising agencies have been facing, advertising agencies move beyond the traditional organization and management and recognize the importance of social media - new channels of communication, interactions, and activities. Social media is a valuable platform and tool for advertising agencies, including their environment to collaborate, create, share, and communicate.

The organizational challenges discussed above undoubtedly have implications for advertising agencies, their leaders, and managers. Any changes to their working practices and organizational activities require understanding new situations, roles, and perspectives.

\section{Social Media and Creativity in the Impact Phase}

Advertising agencies as professional services firms provide knowledge and expertise, and with the accelerated growth of social media, they face different challenges and opportunities (Lee, and Cho, 2020. Truong et al., 2010). Social media has permitted advertisers to interact with consumers and provide them with a richer experience through attaining direct feedback and content exchange, valuable viral advertising, and relationship building (Lee and Cho, 2020; Ashley and Tuten, 2015). Moreover, social media has led to a fragmentation of consumers, making it more difficult in some respects for advertisers to reach their target audience (Gensler et al., 2013). The more complex and blurred line has been placed between media and agency services in traditional and digital spaces, significantly impacting communication strategies.

Social media has significant strategic implications for advertising agencies' business and the advertising ecosystem. Even though an advertising agency may initiate new services, collaboration, or partnerships, this cannot be done in isolation from the environment (Durkin and Lawlor, 2001). Agencies have various relationships with business partners and stakeholders to be maintained, developed, or transformed (Durkin and Lawlor, 2001; Freytag and Clarke, 2012; Horsky, 2006; Argueta and Pérez-Latre, 2018). Often a change in an advertising agency in which strategy is embedded requires developing a new business model - changes in existing collaborations, the development of new collaborations, and the termination of some existing collaborations at a certain point in time. Strategic activities are embedded in an advertising agency, and it may be a resource and time-consuming to make changes as it is difficult to establish, change and disrupt collaborations (Freytag and Clarke, 2012; Stuhlfaut and Windels, 2019). Nevertheless, as value is often co-produced in interaction with other business partners or stakeholders, the possibilities and limits of the agency depend on interaction with other actors of the firm and with actors from other firms (Durkin and Lawlor, 2001). 


\section{DISCUSSION}

\section{Creativity Management Transformation Due to Social Media}

Creativity is the foundation of the advertising profession (Smith and Yang, 2004). Agency creativity as an integral part of advertising creativity refers to the creative quality of agency teams in creating innovative ads (Pratt, 2006), which is why most advertising agencies emphasize creativity as their fundamental strategy. Therefore, creativity management is crucial in advertising agency organization and operation.

Changes in the advertising environment have accelerated the need for creativity management transformation (Hackley and Kover, 2007). However, rapid developments in technology and social media increase consumer empowerment and engagement levels have led to the blurring of boundaries of the creative process and between the activities performed in traditional advertising agencies. Social media has offered a platform for consumers to create content and participate in a conversation and for advertisers to incorporate consumer-generated content into advertising campaigns to become co-creators and producers (Krishnamurthy and Dou, 2008; Dessart et al., 2015). Interactions among consumers and brands via social media platforms and the rise of user-generated content is a challenge for advertising agency organizations, more precisely for creativity management. Changes in communication dynamics, collaboration, and possibilities introduce new ways of working and thus new activities for creativity management (Hackley and Kover, 2007).

Creativity management in advertising agencies is a management practice that can improve the innovation process by encouraging agency organizations to act and respond with increased creativity and initiative (Argueta and Pérez-Latre, 2018). Advertising agencies are increasingly searching for new ways to accelerate innovation by encouraging new ideas and initiatives internally and externally through collaboration. Social media has a role in driving and shaping creativity management in an advertising agency, and therefore, it is relevant to consider their valuable odds for the advertising agency's creativity and innovation. Creativity management is essential as leaders and managers increasingly need a framework to initiate and support many initiatives, diverse collaborations, and blurred lines of creation and ideation with a significant role of social media (Figure 2). Figure 2 presents creativity management that includes capturing and delivering value in interaction with social media.

Creativity management, which considers the role of social media, is portrayed as a relationship to jump-start innovation by inducing advertising agency professionals to use interactions for ideas, change, and processes (Xu and Rickards, 2007; Durkin and Lawlor, 2001; Nov and Jones 2006). Thus, creativity management which includes social media as a tool and communication platform, is an expanded framework for creativity management that targets the innovation process, generating new and actionable ideas.

The importance of creativity management is to provide the framework for activities to capture value from the environment (e.g., information, collaboration, co-creation) and deliver high value to a sizeable market (e.g., communication, campaign). With the role of social media, creativity management includes capture- and deliver-value loops that fuel interactions for creativity and innovation. The creative process, capturing and delivering value through the interaction with the environment and stakeholders, is the pursuit of the entire advertising agency. Finding the creativity management framework that supports the right activities and advances the creative process to work and succeed is the responsibility of the agency leadership. However, it is sustainable when employees are invited in to participate. When a creativity management framework is onboard, loops serve for the framework's flexibility, interact, and respond quickly to the needs of the creative process.

The transformation in creativity management due to the role of social media is the modifications of existing processes by activities that implicate the role of social media and new activities to support the development and validation of new ideas, solutions, products, and services. The framework presented below emphasized social media-related activities within creativity management from the perspective of operation, strategy, and organization (Table 1). 
Figure 2. The role of social media in creativity management (Source: Author's illustration, 2021)

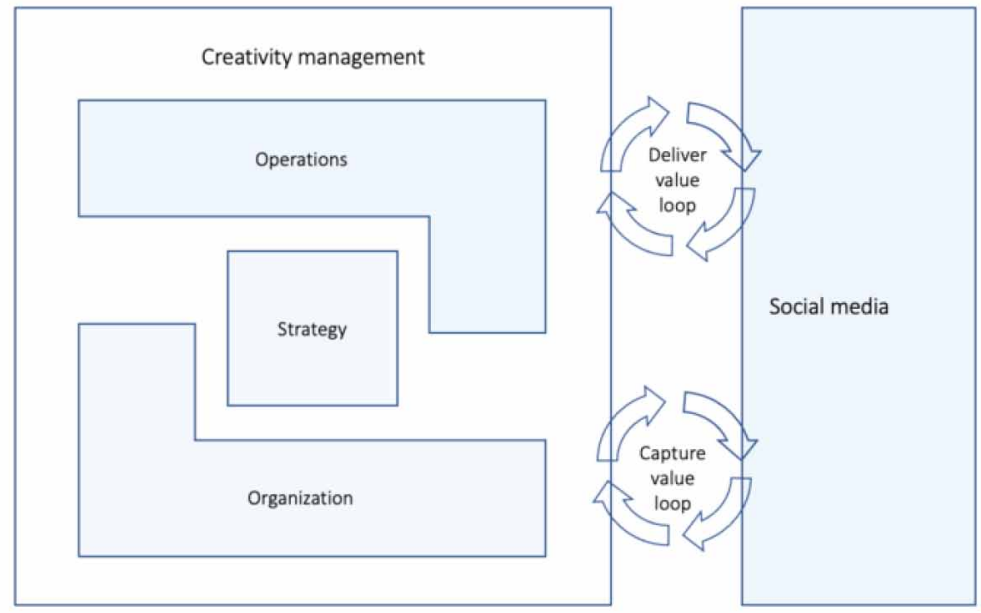

Table 1. Creativity management framework including the role of social media

\begin{tabular}{|c|c|c|c|}
\hline \multicolumn{2}{|c|}{ Creativity management perspective } & Activities & Role of social media \\
\hline \multirow[t]{4}{*}{ Operation } & \multirow{4}{*}{$\begin{array}{l}\text { - use of social media features and } \\
\text { implementation of these features to } \\
\text { enable new technologies to amplify } \\
\text { creativity and innovation to achieve } \\
\text { business goals }\end{array}$} & Information & \multirow{4}{*}{$\begin{array}{l}\text { - provids facts or learning about the exact } \\
\text { topic, need or job to be done } \\
\text { - engages a group for a common goal, e.g., } \\
\text { ideation, problem-solving, or efficiency } \\
\text { - enables exchanging of information } \\
\text { - provides checking or proving the validity } \\
\text { or accuracy of an idea, product, or service }\end{array}$} \\
\hline & & Crowdsourcing & \\
\hline & & Communication & \\
\hline & & Validation & \\
\hline \multirow[t]{4}{*}{ Strategy } & \multirow{4}{*}{$\begin{array}{l}\text { - use of social media and creation } \\
\text { of strategies that best meet agency } \\
\text { needs or achieve their business } \\
\text { goals }\end{array}$} & Partnerships & \multirow{4}{*}{$\begin{array}{l}\text { - enables an arrangement by two or more } \\
\text { parties to manage and operate a business } \\
\text { - enables the process of working together } \\
\text { to complete a task or achieve a goal } \\
\text { - enables discovering and realizing new } \\
\text { services } \\
\text { - enables discovering and realizing new } \\
\text { markets }\end{array}$} \\
\hline & & Collaborations & \\
\hline & & New services & \\
\hline & & New markets & \\
\hline \multirow[t]{4}{*}{ Organization } & \multirow{4}{*}{$\begin{array}{l}\text { - management and allocation of } \\
\text { processes, talents, and technology } \\
\text { needed to develop, deploy, use, and } \\
\text { interact with social media to meet } \\
\text { their needs or achieve business } \\
\text { goals }\end{array}$} & Culture & \multirow{4}{*}{$\begin{array}{l}\text { - enables and enriches employees' } \\
\text { cognitive processes and support } \\
\text { conversational and collaborative processes } \\
\text { - enables exchanging of information } \\
\text { - enables to tap into a vast pool of talents } \\
\text { - enables and enriches employees' } \\
\text { cognitive processes and support } \\
\text { conversational and collaborative processes }\end{array}$} \\
\hline & & Communication & \\
\hline & & $\begin{array}{l}\text { Talent } \\
\text { management }\end{array}$ & \\
\hline & & Learning & \\
\hline
\end{tabular}

Source: author, 2021

The framework endorses the position of Sigala and Chalkiti that "social media significantly support innovation processes by changing the way people search, read, share, and discuss information" (Sigala and Chalkiti 2015, pp.56). The use of social media in creativity management empowers 
people to engage conversationally and collaboratively, which in turn enriches employees' cognitive and creative processes.

The framework incorporates activities for creativity management within an advertising agency, which is necessary for competing in today's markets. In the operations, social media amplify creativity and innovation by enabling information from the market or consumers, crowdsourcing ideas or solutions, exchanging information among stakeholders, and providing validation for ideas or solutions. The use of social media to create strategies is focused on enabling effective partnerships, collaborative work on various projects, discovering and realizing new markets and services. Social media in the organization space enables and enrich employees' cognitive processes (e.g., searching, storing, and reading information) and support conversational and collaborative processes (e.g., sharing, discussing, and synthesizing information from various networks) with a purpose to fuel and enhance creative processes and outcomes.

A collaborative team creates advertising campaigns within and beyond advertising agencies, including various contracted or freelance professionals (West et al. 2019, Hipperson, 2012; Turnbull and Wheeler, 2016). Combining different talents with diverse skills and specialized work areas also brings their tastes and interests to their creative organizations. The advertising creatives, including artists, copywriters, art directors, and creative directors, have long played an essential role in creative idea generation and creative production, bringing advertising ideas to life and managing the creative process. Therefore, the skill sets employed by creatives in realizing creative strategies and advertising campaigns are crucial in maintaining excellence in advertising (Puccio et al., 2010; Rickards and Moger, 2006).

\section{Practical Implications}

Social media has increased the need for creative managers to handle the various activities needed to drive the change through an emerging future. Business and media landscape complexity has risen dramatically stakeholder expectations beyond the obvious from advertising agencies (Durkin and Lawlor, 2001; Turnbull and Wheeler, 2016). Creativity management means being competent in solving problems, encourage activities, and manage change in uncertain times - an intersection where creativity and management increase their importance and presence in the advertising agency business.

Creativity management requires new knowledge, skills, and tools to maximize the benefits of new opportunities and improved ways of working (Xu and Rickards, 2007). Creativity and innovation are essential for an advertising agency's business (Turnbull and Wheeler, 2016), and therefore, the creativity management framework supports activities enabled by new technologies and social media to make the business sustainable. However, no matter where the organization of the advertising agency stands on the readiness of creativity and innovation within creativity management, the following elements and skills could play a role in the future of creative problem-solving:

- Integrative thinking can help expand the boundaries of possibility as a problem-solving approach that uses conflicting ideas as a basis for innovation (Martin, 2009). It is based on the ability to keep a range of different and conflicting data and models in mind and exploit the tension that creates the encouragement of innovative solutions.

- Business design uses principles and practices of design to help organizations create new value and new forms of competitive advantage (Norman and Verganti, 2014). A human-centered approach to innovation works at the intersection of customer empathy, experience design, and business strategy.

- Change management is a methodical approach to managing and implementing strategies for effecting change, controlling change, and helping organizations adapt to change (Kotter, 2012). As business continues to evolve and accelerate, managers need a change management mindset to tackle complex challenges, navigate uncertainty and manage change all the time (Kotter, 2012). 
The advertising agency environment has become complex, and there is a need to manage constant change, make strategic decisions, and incentivize creativity and opportunities for innovation.

- The fearless organization because creativity management requires an environment that provides psychological safety (Edmondson, 2018). According to Edmondson, for innovation to thrive, organizations need psychological safety for creativity, learning, and belonging (Edmondson, 2018).

\section{CONCLUSION}

This paper has examined the emergence of social media and how it has influenced creativity management in an advertising agency. The rise of social media has led to many changes within the advertising industry and, therefore, the role of advertising creatives specifically. Although advances in social media significantly support creativity in advertising agencies by changing the way people search, create, share, and interact with information (Hanna et al., 2011; Kaplan and Haenlein, 2010), no research has yet examined social media's role in creativity management. By exploiting a creativity management framework approach, this study explained the role of social media on creativity management by showing how social media can enrich the advertising agency operations, strategy, and organization, introducing and supporting activities for the creative process. The paper also contributes to the advertising agency creativity literature by providing a framework for delivering and capturing relations and interactions with social media. Moreover, the paper provided a few practical implications about exploiting social media for the advertising agency creativity process. The findings also provided valuable ideas for advancing research even further.

It is no longer enough to merely include social media as a communication channel and as an element of a marketing plan. Instead, advertising agencies need to include social media as part of creativity management whereby its activities work together toward a common objective - whether to understand market needs or reactions, communicate a product or service, or further engage stakeholders in a meaningful and interactive dialogue.

Overall, the main implication of this paper is the growing need to expand the emphasis in creativity management from managing creative individuals and creative processes to understanding and using the capabilities of social media in the context of activities and management. Furthermore, research should extend from relatively constant elements that determine creativity in an advertising agency to understand and manage the dynamic interactions of activities in an organization and the creative process that increases the creativity of agency individuals and organizations.

As social media continue to advance, new social media platforms have emerged, and marketing communication opportunities have arisen. Social media has a role in driving and shaping creativity management in an advertising agency, and it is essential to look at its implications for the advertising industry. Successful advertising agency management today relies heavily on someone's ability to answer effectively and proactively drive positive change (Puccio et al., 2010). Hence, successful leaders manage change, lead organization, talents, and collaboration by navigating uncertainty for growth.

This study has limitations that lead to a recommendation for future research and provides an overview of how creative management can be improved with the role of social media. Today, many advertising agencies have found a specific way to use social media as part of their business, but like many firms use social media as a communication channel but have difficulty using social media for creative and innovation purposes (Roberts and Piller, 2016). Future research could include interviews with advertising agency managers and creative leaders to further develop and test the framework. The second limitation is the fast-changing technological innovations and accelerated social media progress, which implicates the constant introduction of novel possibilities for creativity management and continued research in the future.

Today opportunities and competitive advantage can disappear with a pace of change, and for advertising agencies, it means the transformation of creativity management - to introduce and support 
activities on the future-readiness spectrum. As technology progresses rapidly and the way people interact with social media is changing, this environment implicates how the advertising agency is organized and creativity is managed. Therefore, further research is required to understand better the dynamic interactions of creativity management and social media's role in the agency's creative process. 


\section{REFERENCES}

Ackoff, R. L., \& Greenberg, D. (2008). Turning Learning Right Side Up: Putting Education Back on Track. Pearson.

Alalwan, A. A. (2018). Investigating the impact of social media advertising features on customer purchase intention. International Journal of Information Management, 42, 65-77. doi:10.1016/j.ijinfomgt.2018.06.001

Amabile, T. M. (1997). Motivating creativity in organizations: On doing what you love and loving what you do. California Management Review, 40(1), 39-58. doi:10.2307/41165921

Anderson, N., Potočnik, K., \& Zhou, J. (2014). Innovation and creativity in organizations: A state-of-thescience review, prospective commentary, and guiding framework. Journal of Management, 40(5), 1297-1333. doi:10.1177/0149206314527128

Anderson, P., \& Tushman, M. L. (1990). Technological discontinuities and dominant designs: A cyclical model of technological change. Administrative Science Quarterly, 35(4), 604-633. doi:10.2307/2393511

Argueta, J. K., \& Pérez-Latre, F. J. (2018). The Transformation of Advertising Agencies in a Digital World. In Handbook of Media Management and Economics. Routledge.

Ashley, C., \& Tuten, T. (2015). Creative strategies in social media marketing: An exploratory study of branded social content and consumer engagement. Psychology and Marketing, 32(1), 15-27. doi:10.1002/mar.20761

Basadur, M. (2004). Leading others to think innovatively together: Creative leadership. The Leadership Quarterly, 15(1), 103-121. doi:10.1016/j.leaqua.2003.12.007

Berners-Lee, T., Hendler, J., \& Lassila, O. (2001). The semantic web. Scientific American, $284(5), 34-43$. doi:10.1038/scientificamerican0501-34 PMID:11681174

Boyd, D. M., \& Ellison, N. B. (2007). Social network sites: Definition, history, and scholarship. Journal of Computer-Mediated Communication, 13(1), 210-230. doi:10.1111/j.1083-6101.2007.00393.x

Creeber, G., \& Martin, R. (2008). Digital culture: Understanding new media. McGraw-Hill Education.

de Waal Malefyt, T., \& Morais, R. J. (2010). Creativity, brands, and the ritual process: Confrontation and resolution in advertising agencies. Culture and Organization, 16(4), 333-347. doi:10.1080/14759551.2010.519927

Dessart, L., Veloutsou, C., \& Morgan-Thomas, A. (2015). Consumer engagement in online brand communities: A social media perspective. Journal of Product and Brand Management, 24(1), 28-42. doi:10.1108/JPBM-062014-0635

Deuze, M. (2007). Convergence Culture in Creative Industry. International Journal of Cultural Studies, 10(2), 243-252. doi:10.1177/1367877907076793

Di Gangi, P. M., \& Wasko, M. (2009). Steal my idea! Organizational adoption of user innovations from a user innovation community: A case study of Dell IdeaStorm. Decision Support Systems, 48(1), 303-312. doi:10.1016/j. dss.2009.04.004

Durkin, M., \& Lawlor, M. A. (2001). The implications of the Internet on the advertising agency-client relationship. Service Industries Journal, 2(2), 175-190. doi:10.1080/714005026

Dwivedi, Y. K., Kapoor, K. K., \& Chen, H. (2015). Social media marketing and advertising. The Marketing Review, 15(3), 289-309. doi:10.1362/146934715X14441363377999

Edmondson, A. C. (2018). The fearless organization: Creating psychological safety in the workplace for learning, innovation, and growth. John Wiley \& Sons.

Freytag, P. V., \& Clarke, A. H. (2012). Understanding change in industry and business models-On the changing role of advertising agencies. In IMP Conference, Rome, Italy.

Gensler, S., Völckner, F., Liu-Thompkins, Y., \& Wiertz, C. (2013). Managing brands in the social media environment. Journal of Interactive Marketing, 27(4), 242-256. doi:10.1016/j.intmar.2013.09.004 
Ha, L. (2008). Online advertising research in advertising journals: A review. Journal of Current Issues and Research in Advertising, 30(1), 31-48. doi:10.1080/10641734.2008.10505236

Hackley, C., \& Kover, A. J. (2007). The trouble with creatives: Negotiating creative identity in advertising agencies. International Journal of Advertising, 26(1), 63-78. doi:10.1080/02650487.2007.11072996

Hanna, R., Rohm, A., \& Crittenden, V. L. (2011). We're all connected: The power of the social media ecosystem. Business Horizons, 54(3), 265-273. doi:10.1016/j.bushor.2011.01.007

Hipperson, T. (2012). The future structure of agencies. Available at: https://fdocuments.in/document/the-futurestructure-of-agencies.html

Holt, D. (2016). Branding in the age of social media. Harvard Business Review, 94(3), 40-50.

Horsky, S. (2006). The changing architecture of advertising agencies. Marketing Science, 25(4), $367-383$. doi: $10.1287 / \mathrm{mksc} .1060 .0198$

IPA. (2019). Social media habits. Institute of Practitioners in Advertising. Available at: https://ipa.co.uk/ media/8705/tp_making_sense_2019_report_v2.pdf

Jothi, P.S., Neelamalar, M., \& Prasad, R.S. (2011). Analysis of social networking sites: A study on effective communication strategy in developing brand communication. Journal of Media and Communication Studies, 3(7), 234-242.

Kaplan, A. M., \& Haenlein, M. (2010). Users of the world, unite! The challenges and opportunities of Social Media. Business Horizons, 53(1), 59-68. doi:10.1016/j.bushor.2009.09.003

Kaplan, A. M., \& Haenlein, M. (2012). Social media: Back to the roots and back to the future. Journal of Systems and Information Technology, 14(2), 101-104. doi:10.1108/13287261211232126

Kašćelan, L., Pejić Bach, M., Rondović, B., \& Đuričković, T. (2020). The interaction between social media, knowledge management and service quality: A decision tree analysis. PLoS One, 15(8), e0236735. doi:10.1371/ journal.pone.0236735 PMID:32745126

Khang, H., Ki, E.-J., \& Ye, L. (2012). Social media research in advertising, communication, marketing, and public relations, 1997-2010. Journalism \& Mass Communication Quarterly, 89(2), 279-298. doi:10.1177/1077699012439853

Kim, J., \& McMillan, S. J. (2008). Evaluation of Internet advertising research: A bibliometric analysis of citations from key sources. Journal of Advertising, 37(1), 99-112. doi:10.2753/JOA0091-3367370108

Knoll, J. (2016). Advertising in Social Media: A Review of Empirical Evidence. International Journal of Advertising, 35(2), 266-300. doi:10.1080/02650487.2015.1021898

Kotler, P., \& Lee, N. (2008). Social marketing: Influencing behaviors for good. Sage Publications.

Kotter, J. P. (2012). Leading change. Harvard Business Press.

Krishnamurthy, S., \& Dou, W. (2008). Advertising with User-Generated Content: A Framework and Research Agenda. Journal of Interactive Advertising, 8(2), 1-7. doi:10.1080/15252019.2008.10722137

Lee, H., \& Cho, C. H. (2020). Digital advertising: Present and future prospects. International Journal of Advertising, 39(3), 332-341. doi:10.1080/02650487.2019.1642015

Lee, J., \& Hong, I. B. (2016). Predicting positive user responses to social media advertising: The roles of emotional appeal, informativeness, and creativity. International Journal of Information Management, 36(3), 360-373. doi:10.1016/j.ijinfomgt.2016.01.001

Leonard-Barton, D. (1992). Core capabilities and core rigidities: A paradox in managing new product development. Strategic Management Journal, 13(1), 111-125. doi:10.1002/smj.4250131009

Li, H. (2011). The interactive web: Toward a new discipline. Journal of Advertising Research, 51(1), 13-26. doi:10.2501/JAR-51-1-013-026 
Lim, S., \& Reeves, B. (2010). Computer agents versus avatars: Responses to interactive game characters controlled by a computer or other player. International Journal of Human-Computer Studies, 68(1-2), 57-68. doi:10.1016/j.jhhcs.2009.09.008

Makri, M., \& Scandura, T. A. (2010). Exploring the effects of creative CEO leadership on innovation in hightechnology firms. The Leadership Quarterly, 21(1), 75-88. doi:10.1016/j.leaqua.2009.10.006

Mangold, W. G., \& Faulds, D. J. (2009). Social media: The new hybrid element of the promotion mix. Business Horizons, 52(4), 357-365. doi:10.1016/j.bushor.2009.03.002

Martin, R. L. (2009). The opposable mind: How successful leaders win through integrative thinking. Harvard Business Press.

Miller, V. (2020). Understanding digital culture. Sage Publications.

Montalvo, R. E. (2011). Social media management. International Journal of Management \& Information Systems, 15(3), 91-96.

Norman, D. A., \& Verganti, R. (2014). Incremental and radical innovation: Design research vs. technology and meaning change. Design Issues, 30(1), 78-96. doi:10.1162/DESI_a_00250

Nov, O., \& Jones, M. (2006). Ordering Creativity? Knowledge, Creativity, and Idea Generation in the Advertising Industry. International Journal of Product Development, 3(2), 252-262. doi:10.1504/IJPD.2006.009374

Okazaki, S., \& Taylor, C. R. (2013). Social media and international advertising: Theoretical challenges and future directions. International Marketing Review, 30(1), 56-71. doi:10.1108/02651331311298573

Pejić Bach, M., Pulido, C. M., Suša Vugec, D., Ionescu, V., Redondo-Sama, G., \& Ruiz-Eugenio, L. (2020). Fostering social project impact with Twitter: Current Usage and perspectives. Sustainability, 12(15), 6290. doi: $10.3390 / \mathrm{su} 12156290$

Pratt, A. C. (2006). Advertising and creativity, a governance approach: A case study of creative agencies in London. Environment and Planning A. Economy and Space, 38(10), 1883-1899.

Puccio, G. J., Mance, M., \& Murdock, M. C. (2010). Creative leadership: Skills that drive change. Sage Publications.

Razzouk, R., \& Shute, V. (2012). What is design thinking and why is it important? Review of Educational Research, 82(3), 330-348. doi:10.3102/0034654312457429

Rickards, T., \& Moger, S. (2006). Creative Leaders: A Decade of Contributions from Creativity and Innovation Management Journal. Creativity and Innovation Management, 15(1), 4-18. doi:10.1111/j.1467-8691.2006.00365.x

Roberts, D. L., \& Piller, F. T. (2016). Finding the right role for social media in innovation. MIT Sloan Management Review, 57(3), 41-47.

Roblek, V., Pejić Bach, M., Meško, M., \& Bertoncelj, A. (2013). The impact of social media to value added in knowledge-based industries. Kybernetes, 42(4), 554-568. doi:10.1108/K-01-2013-0014

Shalley, C. E., \& Zhou, J. (2008). Organizational creativity research: A historical overview. In C. E. Shalley \& J. Zhou (Eds.), Handbook of organizational creativity (pp. 7-31). Lawrence Erlbaum.

Sigala, M., \& Chalkiti, K. (2015). Knowledge management, social media and employee creativity. International Journal of Hospitality Management, 45, 44-58. doi:10.1016/j.jhm.2014.11.003

Smith, R. E., \& Yang, X. (2004). Toward a general theory of creativity in advertising: Examining the role of divergence. Marketing Theory, 4(1-2), 31-58. doi:10.1177/1470593104044086

Statista. (2020). Social network penetration worldwide from 2017 to 2025. Available at https://www.statista. com/statistics/260811/social-network-penetration-worldwide/

Steinkuehler, C. A., \& Williams, D. (2006). Where everybody knows your (screen) name: Online games as third places. Journal of Computer-Mediated Communication, 11(4), 885-909. doi:10.1111/j.1083-6101.2006.00300.x 
Stuhlfaut, M. W., \& Windels, K. (2019). Altered states: The effects of media and technology on the creative process in advertising agencies. Journal of Marketing Communications, 25(1), 1-27. doi:10.1080/13527266. 2017.1380069

Tajudeen, F. P., Jaafar, N. I., \& Ainin, S. (2018). Understanding the impact of social media usage among organizations. Information \& Management, 55(3), 308-321. doi:10.1016/j.im.2017.08.004

Tapp, A., \& Hughes, T. (2004). New technology and the changing role of marketing. Marketing Intelligence \& Planning, 22(3), 284-296. doi:10.1108/02634500410536876

Truong, Y., McColl, R., \& Kitchen, P. (2010). Practitioners' Perceptions of Advertising Strategies for Digital Media. International Journal of Advertising, 29(5), 709-725. doi:10.2501/S0265048710201439

Turnbull, S., \& Wheeler, C. (2016). Exploring advertiser's expectations of advertising agency services. Journal of Marketing Communications, 22(6), 587-601. doi:10.1080/13527266.2014.920902

Voorveld, H. A., Van Noort, G., Muntinga, D. G., \& Bronner, F. (2018). Engagement with social media and social media advertising: The differentiating role of platform type. Journal of Advertising, 47(1), 38-54. doi:1 $0.1080 / 00913367.2017 .1405754$

WARC. (2021). Global Ad Trends: State of The Industry 2020/21. Available at: https://lp.warc.com/global-adtrends-state-of-the-industry-2020-2021

West, D., Koslow, S., \& Kilgour, M. (2019). Future directions for advertising creativity research. Journal of Advertising, 48(1), 102-114. doi:10.1080/00913367.2019.1585307

Wind, Y. J., \& Sharp, B. (2009). Advertising empirical generalizations: Implications for research and action. Journal of Advertising Research, 49(2), 246-252. doi:10.2501/S0021849909090369

Xu, F., \& Rickards, T. (2007). Creative management: A predicted development from research into creativity and management. Creativity and Innovation Management, 16(3), 216-228. doi:10.1111/j.1467-8691.2007.00445.x

Zhou, J. (2008). New look at creativity in the entrepreneurial process. Strategic Entrepreneurship Journal, 2(1), 1-5. doi:10.1002/sej.38

Andrea Rubik, MSc, is a PhD student at the Faculty of Economics and Business, University of Zagreb, Croatia, and a consultant at Odit. She completed her bachelor's studies in Marketing and finished her Master of Science study at the Faculty of Economics and Business, University of Zagreb. Her primary research includes corporate social responsibility, creativity and innovation, design thinking, management innovation, and change management. 